\title{
Open discussion of negative emissions is urgently needed
}

\author{
Although nearly all $2{ }^{\circ} \mathrm{C}$ scenarios use negative $\mathrm{CO}_{2}$ emission technologies, only relatively small investments are \\ being made in them, and concerns are being raised regarding their large-scale use. If no explicit policy decisions are \\ taken soon, however, their use will simply be forced on us to meet the Paris climate targets.
}

\author{
Detlef P. van Vuuren, Andries F. Hof, Mariësse A. E. van Sluisveld and Keywan Riahi
}

\section{1} he 2015 Paris Agreement represents a landmark in international climate policy and carries key implications for energy policies around the world. Several studies have shown that drastic changes in energy systems are needed to achieve the Paris climate objectives of limiting the increase of global mean temperature to well below $2{ }^{\circ} \mathrm{C}$, or possibly even below $1.5^{\circ} \mathrm{C}\left(\mathrm{refs}^{1-3}\right)$. The current literature, which focuses mostly on the $2{ }^{\circ} \mathrm{C}$ target, discusses how these transitions depend on differences in assumptions regarding inertia ${ }^{4}$, participation of regions ${ }^{1,5}$, and the availability and potential of relevant technologies ${ }^{6,7}$. Based on an assessment of a database of published scenarios developed by integrated assessment models (IAMs), the Working Group III (WGIII) contribution to the recent IPCC Fifth Assessment Report (AR5) concluded that scenarios that are likely to maintain warming below $2{ }^{\circ} \mathrm{C}$ "are characterized by 40 to $70 \%$ global anthropogenic greenhouse gas (GHG) emissions reductions by 2050 compared to 2010, and emissions levels near zero or below in 2100 " ${ }^{8}$. These ranges have been quoted frequently in the sphere of international policymaking 9 , but the assumptions supporting the figures are quoted much less frequently. A crucial assumption in this regard relates to the availability of options that can lead to net removal of $\mathrm{CO}_{2}$ from the atmosphere. In fact, of the approximately 110 scenarios in the AR5 WGIII database that are relevant for achieving the $2{ }^{\circ} \mathrm{C}$ target, practically all achieve net negative $\mathrm{CO}_{2}$ emissions in the second half of the century through extensive application of bioenergy with carbon capture and storage (BECCS) $)^{3,10}$. BECCS and other negative emission technologies (NETs) such as forestry policies and direct air capture are very competitive in costoptimization models, leading to their largescale deployment. There are two reasons for this. First, they can balance out excess GHG emissions in the first half of the century, thereby preventing the more drastic and costly emission reductions in the short term that would be needed without NETs (and which entail a considerable risk of ending up with stranded assets) $)^{3,11-13}$. The preference for reducing emissions later in the century is strengthened by the fact that models usually apply a discount rate, typically around $5 \%$. Second, NETs can offset emissions that are hard to reduce in other sectors, such as in transport and agriculture. Overall indicators on deep mitigation scenarios, such as the 2050 reduction rate mentioned above, are therefore dominated by scenarios that include the implementation of NETs.

\section{No NETs means faster reductions}

A closer look at the IPCC scenario database reveals how important the implementation of NETs is for the timing of mitigation efforts (Fig. 1). Scenarios with net negative $\mathrm{CO}_{2}$ emissions require a $40-60 \%$ reduction for all GHG emissions globally by 2050 relative to 2010 . However, the few $2{ }^{\circ} \mathrm{C}$ scenarios without net negative $\mathrm{CO}_{2}$ emissions included in the AR5 database require a much larger reduction globally by 2050 , in the range of $60-75 \%$. For $\mathrm{CO}_{2}$ specifically, rather than all GHGs combined, the requirements are even more stringent. $\mathrm{CO}_{2}$ emissions are to be reduced by $60-85 \%$ by 2050 if NETs are implemented, and by $70-95 \%$ if not. These higher percentages for $\mathrm{CO}_{2}$ are due to the fact that very deep reductions of other GHGs, such as methane and nitrous oxide, are more difficult to achieve ${ }^{14}$. If NETs are not implemented, the inevitable conclusion is that, given the lifetime of most energy infrastructure, not only is an immediate decarbonization of new investments needed, but most likely also a premature replacement of existing capital.

Clear differences also exist between strategies with and without net negative $\mathrm{CO}_{2}$ emissions in terms of energy system deployment strategies. While scenarios with large-scale use of NETs already depict a rapid increase in the deployment of renewable sources, CCS, nuclear power, and energy efficiency technologies, the scenarios that minimize NETs use require an even more rapid deployment of these (Fig. 1d-f). To put this in figures, the decarbonized proportion of the global power supply would need to increase from $30 \%$ today to almost $60 \%$ by 2030 in a scenario with NETs, and to almost $80 \%$ in scenarios without (Fig. 1f). These values underline the fact that without NETS the ambition levels need to be upscaled even more drastically, but that in both cases future decarbonization rates are higher than those currently formulated in the mitigation action plans submitted by Parties under the Paris Agreement ${ }^{15}$.

\section{Technological feasibility}

BECCS and other negative $\mathrm{CO}_{2}$ emission technologies used in scenario analyses have been criticized as speculative $e^{10,16,17}$. It is true that, so far, NETs have not been implemented at a large scale. However, in terms of technology development per se, development needs for BECCS do not seem overly challenging ${ }^{18}$, and other technologies also face similar technical and infrastructural challenges if they are to be scaled up to levels consistent with the $2{ }^{\circ} \mathrm{C}$ scenarios-a typical example being the intermittency issues of renewable energy sources $^{19,20}$. For BECCS, key challenges include scaling up both the infrastructure for large-scale bioenergy supply and $\mathrm{CO}_{2}$ transport $^{21}$. Still, overall, studies suggest that the technological assumptions about CCS in IAMs (such as the existence of effective carbon capture technology) are not unrealistic ${ }^{22}$. At the same time, the most important physical limitations for BECCS are probably not technology related, but rather involve the impacts that large-scale bioenergy production are expected to have on food security and biodiversity, and the presence of safe $\mathrm{CO}_{2}$ storage capacity ${ }^{18,21,23-26}$. These impacts depend on a wide range of 


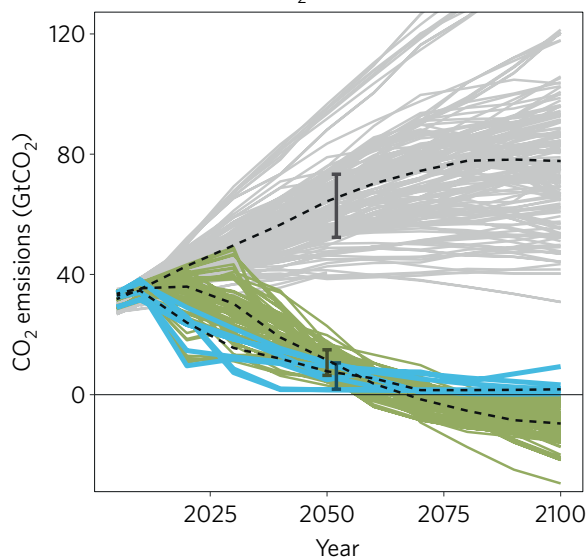

d

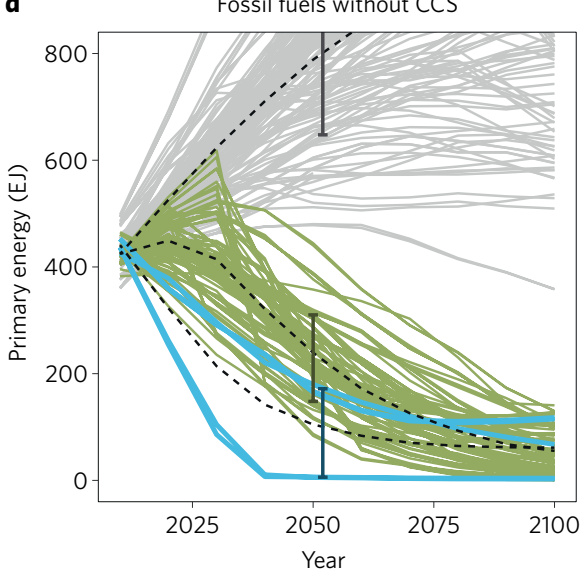

Scenario

- Baseline

$-2{ }^{\circ} \mathrm{C}$ (incl. net negative emissions)

$-2^{\circ} \mathrm{C}$ (excl. net negative emissions) b

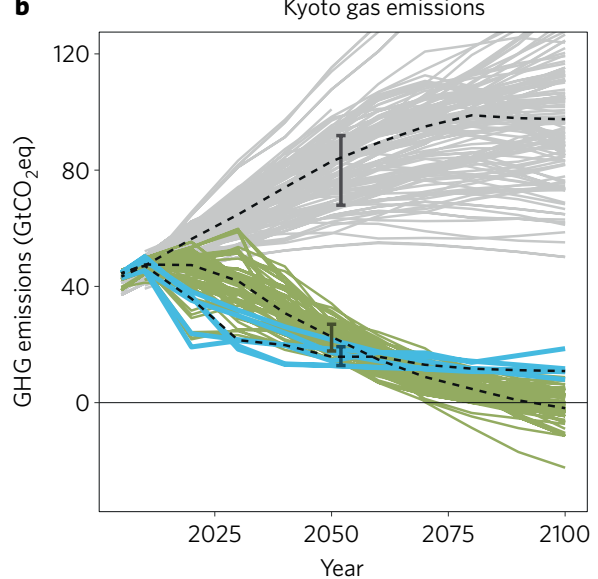

e

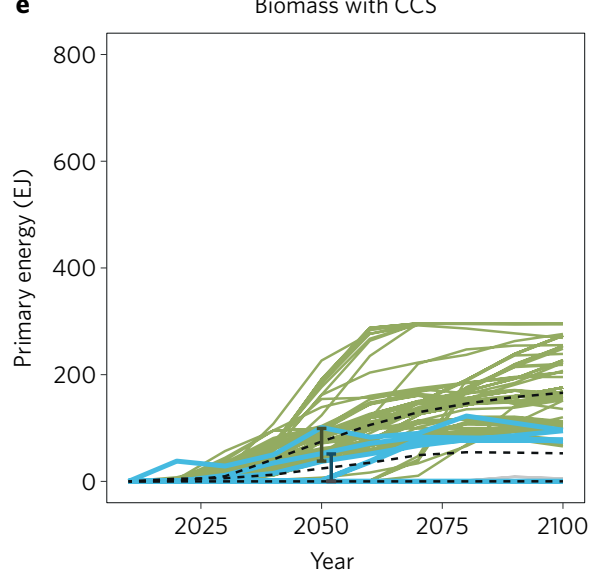

c

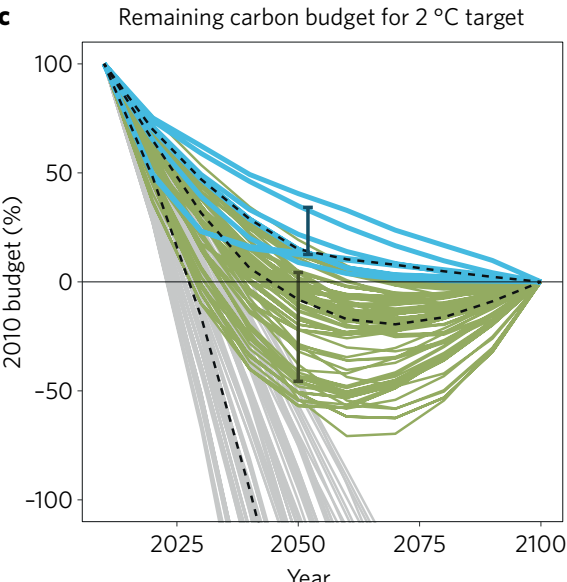

f

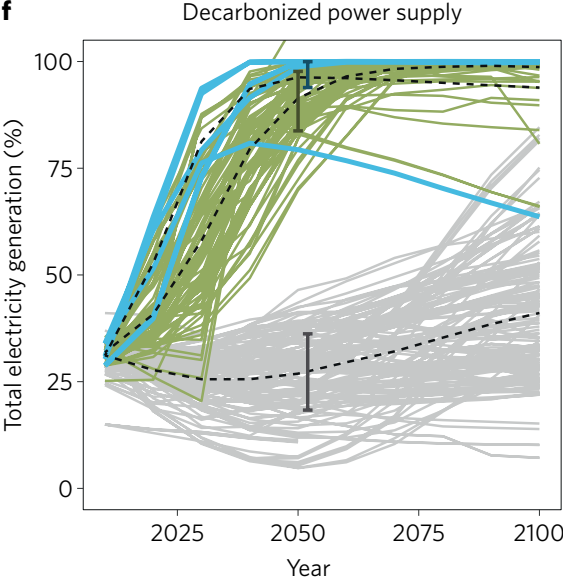

Emission reductions in 2050 relative to 2010 levels (ranges in $\mathbf{a}, \mathbf{b}$ ):

$\begin{array}{lcr}\text { Baseline } & -119 \text { to }-49 \% & -95 \text { to }-47 \% \\ 2{ }^{\circ} \mathrm{C} \text { (incl. net negative emissions) } & 57 \text { to } 83 \% & 41 \text { to } 62 \% \\ 2{ }^{\circ} \mathrm{C} \text { (excl. net negative emissions) } & 67 \text { to } 95 \% & 58 \text { to } 75 \%\end{array}$

Fig. 1 | Greenhouse gas emissions and energy system implications under baseline and $2{ }^{\circ} \mathrm{C}$ scenarios with and without net negative $\mathrm{CO}_{2}$ emissions. a, $\mathrm{CO}_{2}$ emissions. $\mathbf{b}$, Kyoto gas emissions $\left(\mathrm{CO}_{2}, \mathrm{CH}_{4}, \mathrm{~N}_{2} \mathrm{O}\right.$, hydrofluorocarbons, perfluorocarbons and $\left.\mathrm{SF}_{6}\right)$ and $\mathbf{c}$, the ratio between cumulative emissions and the total $\mathrm{CO}_{2}$ budget of each scenario from the AR5 database over the 2010-2100 period. d-f, Implications for the energy system: unabated use of fossil fuels (d), biomass with CCS (e) and decarbonized power supply (f). Data shown are obtained from the IPCC AR5 scenario database. In each panel, the vertical bars show the 15-85th percentile. Baseline scenarios are shown as grey lines. Green and blue lines, respectively, show scenarios in the category leading to a concentration of $430-480 \mathrm{ppm} \mathrm{CO}$ equivalent (corresponding to a probable change of staying below $2^{\circ} \mathrm{C}$ ), with and without net negative $\mathrm{CO}_{2}$ emissions $\mathrm{C}^{3,41}$. Dotted lines refer to the average value in each category. The legend summarizes the emission reductions in 2050 compared to 2010 for $\mathrm{CO}_{2}$ and $\mathrm{Kyoto}$ gas emissions (15-85th percentile) as shown by the vertical bars in panel $\mathbf{a}$ and $\mathbf{b}$, respectively (negative values indicate an increase compared to 2010).

factors, including future developments in agricultural yield. Interestingly, because scenarios not using NETs require a deeper and earlier decarbonization of energy use to reach the $2{ }^{\circ} \mathrm{C}$ target, the scenario literature shows that bioenergy use in this case is also likely to be extensive, mainly to decarbonize transport (as emissions in difficult-to-abate sectors cannot be compensated any more by BECCS). In other words, careful consideration and strict monitoring of the possible impacts of bioenergy will be needed both with and without the use of BECCS. The prospects for safe and sufficient $\mathrm{CO}_{2}$ storage capacity seem promising, but are also still uncertain, especially for options other than the use of empty oil and natural gas reservoirs ${ }^{27-29}$.

A possibly much more problematic factor than technological feasibility, certainly in the short term, is the lack of societal and governmental support for $\mathrm{CCS}^{22,30-32}$. Several CCS demonstration projects proposed in the past few years (such as Barendrecht in the Netherlands and Peterhead in the UK) have been cancelled because of public opposition or lack of broad political support ${ }^{31,33}$, although other projects have been more successful $^{34,35}$. Another constraint is that, while BECCS might (at some point in time) be economical from a macro-economic perspective, it is not yet clear how markets should be organized in the real world to take into account negative emissions ${ }^{18,36}$.

\section{Possible lock-in}

These uncertainties, combined with the observation that the few technologies that can bring about negative emissions share similar characteristics (for example, the huge demand for land for BECCS and afforestation, and large-scale $\mathrm{CO}_{2}$ storage 
for BECCS and direct air capture), lead to a final critical point: if we follow the emission pathways with NETs and it becomes clear over time that the (theoretical) potential of NETs cannot be exploited to the levels currently anticipated by the scenarios, there is only little room left for alternative approaches to compensate for the overshoot of the carbon budget. For other low-carbon or zero-carbon technologies, in contrast, there are many more substitutes. Wind power, for example, can be replaced by both photovoltaics and nuclear power, if it performs worse in the future than anticipated in the scenarios.

\section{Implications for policy and research}

The use of NETs after 2050 will have a strong impact on emission reduction strategies in the next decades ${ }^{37}$. Given the tight carbon budget consistent with the $2{ }^{\circ} \mathrm{C}$ target, a timely decision needs to be made on how much we want to limit (or even totally avoid) NETs or not, otherwise $2{ }^{\circ} \mathrm{C}$ might already be beyond reach within a decade. The same decision, but even more urgently, applies for a $1.5^{\circ} \mathrm{C}$ target. In fact, for $1.5^{\circ} \mathrm{C}$, such discussion would realistically focus on how much NETs is acceptable. This poses an acute and very difficult policy challenge, as meeting the Paris targets most likely either means a very rapid immediate decarbonization of the energy system (with no or limited NETs) or accepting the risks associated with pathways relying greatly on NETs. Both pathways face important uncertainties. As part of discussions on strengthening climate and energy policy in the coming years, it will be important for policymakers and other stakeholders, both nationally and internationally, to discuss explicitly the role of NETs in order to make an informed and conscious decision on post-2050 pathways ${ }^{38}$. Such discussions could help provide clarity for near-term energy decisions and investments. If decision-makers come to the conclusion that reliance on NETs should be limited (or even avoided), emission reductions will need to be closer to the upper limit of the mitigation range given by AR5. More precisely, the appropriate emissions target for 2050 to achieve the
$2{ }^{\circ} \mathrm{C}$ target would then be a reduction of at least $60 \%$ below the 2010 levels for all GHGs combined, and 70-95\% for $\mathrm{CO}_{2}$ alone. More stringent emission reductions in the short term will in any scenario provide more flexibility for the use of negative $\mathrm{CO}_{2}$ emissions in the longer term.

If NETs are to be applied extensively, it would help to define the criteria under which NETs are considered acceptable, and as a result also which types of NETs. Moreover, it would also be important to gain more experience with these technologies and start investing in research and development now (as already called for by some policymakers ${ }^{39,40}$ ), even if large-scale deployment and application may not become viable within the next two decades. Policymakers could also consider, for instance, only allowing new coal plants to be built in combination with CCS, or requiring the introduction of a certain percentage of NETs in the operations of fossil fuel or electric power companies.

Finally, for integrated assessment model analyses it is important to explore a wider set of trajectories consistent with achieving the $2{ }^{\circ} \mathrm{C}$ target that take account of the uncertainties around NETs. While IAM modellers typically assume that technologies are deployed on the basis of economic and technical considerations alone, BECCS in particular faces constraints with respect to societal support. The application of a wider set of criteria in model-based scenarios (other than those focussing on full cost optimization) and an exploration of scenarios with more pessimistic assumptions regarding the feasibility and public support for BECCS will allow for a more in-depth and constructive discussion of the relevant issues in the scenario literature, and can help avoid unintended interpretations of the published research.

\section{Detlef P. van Vuuren ${ }^{1,2 *}$, Andries F. Hof ${ }^{1,2}$,} Mariësse A. E. van Sluisveld ${ }^{1,2}$ and Keywan Riahi ${ }^{3}$

${ }^{1}$ PBL Netherlands Environmental Assessment Agency, The Hague, The Netherlands. ${ }^{2}$ Copernicus Institute for Sustainable Development, Utrecht University, Utrecht, The Netherlands. ${ }^{3}$ International Institute for Applied System Analysis, Laxenburg, Austria. *e-mail:Detlef.vanVuuren@pbl.nl
Published online: 4 December 2017

https://doi.org/10.1038/s41560-017-0055-2

References

1. Tavoni, M. et al. Nat. Clim. Change 5, 119-126 (2015).

2. Rogelj, J. et al. Nat. Clim. Change 5, 519-527 (2015).

3. Clarke, L. et al. in Climate Change 2014: Mitigation of Climate Change (eds. Edenhofer, O. et al.) Ch. 6 (IPCC, Cambridge Univ. Press, 2014).

4. Bertram, C. et al. Technol. Forecast. Soc. Change 90, 62-72 (2015)

5. Kriegler, E. et al. Technol. Forecast. Soc. Change $\mathbf{9 0}$, 24-44 (2015).

6. Kriegler, E. et al. Climatic Change 123, 353-367 (2014).

7. Riahi, K. et al. Technol. Forecast. Soc. Change 90, 8-23 (2015).

8. IPCC Climate Change 2014: Synthesis Report (eds Core WritingTeam, Pachauri, R. K. \& Meyer L. A.) (IPCC, 2015).

9. Leaders Declaration G7 Summit 7-8 June 2015 (G7 Germany, 2015).

10. Anderson, K. \& Peters, G. Science 354, 182-183 (2016)

11. Kriegler, E., Edenhofer, O., Reuster, L., Luderer, G. \& Klein, D. Climatic Change 118, 45-57 (2013).

12. van Vuuren, D. P. et al. Climatic Change 118, 15-27 (2013).

13. Azar, C. et al. Climatic Change 100, 195-202 (2010).

14. Gernaat, D. E. H. J. et al. Glob. Environ. Change 33, 142-153 (2015)

15. van Soest, H. L. et al. Climatic Change 142, 491-504 (2017).

16. Anderson, K. Nat. Geosci. 8, 898-900 (2015).

17. Geden, O. Nature 521, 27-28 (2015).

18. Sanchez, D. L. \& Kammen, D. M. Nat. Energy 1, 15002 (2016).

19. Eom, J. et al. Technol. Forecast. Soc. Change 90, 73-88 (2015).

20. Clack, C. T. M. et al. Proc. Natl Acad. Sci. USA 114, 6722-6727 (2017).

21. Fuss, S. et al. Environ. Res. Lett. 11, 115007 (2016).

22. Vaughan, N. E. \& Gough, C. Environ. Res. Lett. 11, 095003 (2016).

23. Smith, P. et al. Nat. Clim. Change 6, 42-50 (2016).

44. Williamson, P. Nature 530, 7589 (2016).

25. Creutzig, F. et al. GCB Bioenergy 7, 916-944 (2015).

26. Peters, G. P. et al. Nat. Clim. Change 7, 118-122 (2017).

27. Pires, J. C. M., Martins, F. G., Alvim-Ferraz, M. C. M. \& Simões, M. Chem. Eng. Res. Design 89, 1446-1460 (2011).

28. Boot-Handford, M. E. et al. Energy Environ. Sci. 7, 130-189 (2014).

29. Koornneef, J. et al. Int. J. Greenhouse Gas Contr. 11, 117-132 (2012),

30. Minx, J. C., Lamb, W. F., Callaghan, M. W., Bornmann, L. \& Fuss, S. Environ. Res. Lett. 12, 035007 (2017).

31. Brunsting, S., De Best-Waldhober, M., Feenstra, C. F. J. \& Mikunda, T. Energy Proc. 4, 6376-6383 (2011).

32. Fridahl, M. Energy Policy 104, 89-99 (2017).

33. Lockwood, T. Public Outreach Approaches for Carbon Capture and Storage Projects (International Energy Agency, Clean Coal Centre, Paris, 2017).

34. CSL Forum Project Summaries (2017); http://go.nature. com/2AEk9U1

35. Global CCS Institute The Global Status of CCS (2016); http://go.nature.com/2AEkqX3

36. Klein, D. et al. Climatic Change 123, 705-718 (2014).

37. van Vuuren, D. P. \& Riahi, K. Climatic Change 104 793-801 (2011).

38. Peters, G. P. \& Geden, O. Nat. Clim. Change 7, 619-621 (2017).

39. Moniz, E. J. \& Falih, K. A. A. Open Letter to the United Nations Framework Convention on Climate Change on CCS (2016).

40. CSL Forum Moving Beyond the First Wave of CCS Demonstrations (2015); http://go.nature.com/2AFfEbx

41. Krey, V. et al. in Climate Change 2014: Mitigation of Climate Change (eds. Edenhofer, O. et al.) Annex II (IPCC, Cambridge Univ. Press, 2014) 